\title{
Homozygosity mapping of a gene for arterial tortuosity syndrome to chromosome $20 \mathrm{q} 13$
}

\author{
P J Coucke, M W Wessels, P Van Acker, R Gardella, S Barlati, P J Willems, M Colombi, \\ A De Paepe
}

J Med Genet 2003;40:747-751

\begin{abstract}
Background: Arterial tortuosity syndrome (ATS) is an uncommon connective tissue disorder of unknown aetiology. The most prominent feature is tortuosity of the large arteries, but lengthening, stenosis, and aneurysm formation are also frequent.

Methods: We performed a genomewide screen by homozygosity mapping of three consanguineous multiplex families, two from Morocco, and one from Italy, which included 11 ATS patients. The two families from Morocco may possibly have a common ancestor.

Results: We mapped the ATS gene to chromosome $20 q 13$. Recombinations within an extended haplotype of 11 microsatellite markers localised the ATS gene between markers D20S836 and D20S109, an interval of $9.5 \mathrm{cM}$.

Conclusions: Cloning and completing functional and structural analysis of the ATS gene may provide new insights into the molecular mechanisms of elastogenesis.
\end{abstract}

A rterial tortuosity syndrome (ATS; MIM 208 050) is a rare connective tissue disorder characterised by generalised tortuosity, elongation, stenosis, and aneurysms of the major arteries. ${ }^{1-9}$ Skin and joint abnormalities, including hyperextensibility or hyperlaxity of the skin, joint laxity or contractures, and inguinal hernias, reminiscent of other connective tissue diseases, can also be observed. Other phenotypic abnormalities include micrognathia, elongated face, high palate, beaked nose, sliding hernia, and ventricular hypertrophy. Histopathological studies show abnormalities of the elastin network in the large arteries. ${ }^{2-5} 7$

The mode of inheritance of ATS is autosomal recessive, but the disease gene has not yet been identified. Recently, the elastin gene and some collagen genes involved in connective tissue disease were excluded as candidate genes in ATS. ${ }^{10}$ Until now, a very limited number of ATS patients have been described, and few multiplex families have been published. However, some inbred multiplex families originating from Morocco $^{9}$ and Italy $^{10}$ have recently been reported. Such families make it possible to localise the ATS gene by positional genetics. This study reports the localisation of the ATS gene by homozygosity mapping in two, and probably three, inbred families.

\section{PATIENTS AND METHODS Families}

The three families, which included 11 ATS patients, originated from Morocco and Italy. All three families are inbred and the parents of all patients are consanguineous (fig 1). The two Moroccan families (family 1 with six affected individuals (IV-2, IV-3, IV-4, IV-5, IV-9, and IV-10) and family 2 with one affected individual (V-3)) might have a common ancestor as they originate from the same town in north Morocco. The clinical picture in these patients consists of tortuosity of the aorta, and pulmonary, subclavian, and renal arteries, as shown by echocardiography, angiography, and/or CT scan (table 1). Additional clinical features present in some of these patients were hyperlax skin and joints, and/ or dilation, aneurysms, and stenosis of the pulmonary arteries and ascending aorta. All these clinical manifestations fit the spectrum of ATS, as reviewed by Wessels. ' The phenotype of one individual (IV-1) in the Moroccan family 1 (fig 1) is unclear because no studies of the major arteries could be performed. The Italian family, originating from south Sicily, has four affected individuals (IV-1, IV-2, IV-4, IV-5). All patients show tortuosity of the major arteries, and two patients (IV-4 and IV-5) also show severe pulmonary artery stenosis. Variable cutaneous, joint, and facial manifestations were observed in all patients (table 1). Occasionally, gastric and inguinal hernias, intestine elongation, and keratoconus were present.

The parents and brother of the ATS patients were clinically normal. The clinical features of the different patients of all three families are described in detail elsewhere. ${ }^{9}{ }^{10}$

Venous blood was taken for genetic studies from all 11 affected individuals, their parents, and healthy siblings. Informed consent was obtained in each instance from the subject and/or a legal guardian.

\section{DNA analysis and pooling strategy}

Genomic DNA was extracted from peripheral blood leukocytes by a standard technique.

A genome search was performed in family 1. To increase the speed of the total genome screen, the DNA samples of the six affected individuals of this Moroccan family were pooled. As it is critical that the pool contains equal quantities of DNA from each individual, DNA quantification was measured by ultraviolet light spectroscopy, followed by quantification on $1 \%$ agarose gels with a lambda quantification standard. Each individual sample was diluted to $50 \mathrm{ng} / \mu \mathrm{l}$ stock solution to avoid viscous solutions. Finally, a control PCR was performed on each sample to make sure that they all yielded the same amount of amplified product. Equimolar amounts of each sample were then combined, and the sample pool was assessed empirically by comparing alleles for several polymorphisms between pooled and individual samples (data not shown).

\section{Homozygosity mapping}

A set of 400 highly polymorphic microsatellite markers (ABI PRISM $^{\mathrm{TM}}$ Linkage Mapping Set Version 2; Applied Biosystems, Foster City, CA, USA) with an average spacing

Abbreviations: ATS, arterial tortuosity syndrome; EDS, Ehlers-Danlos syndrome 


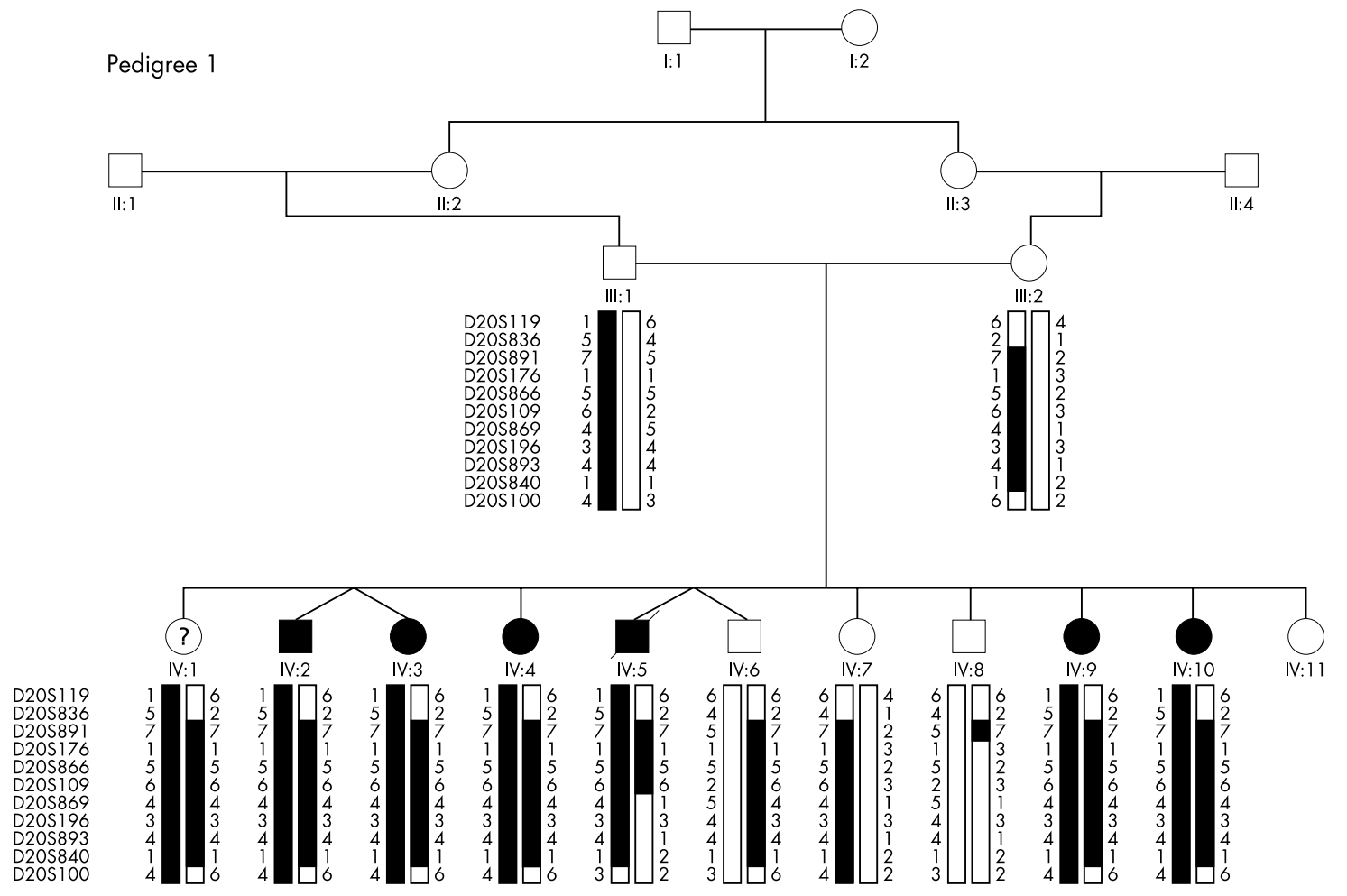

Pedigree 2
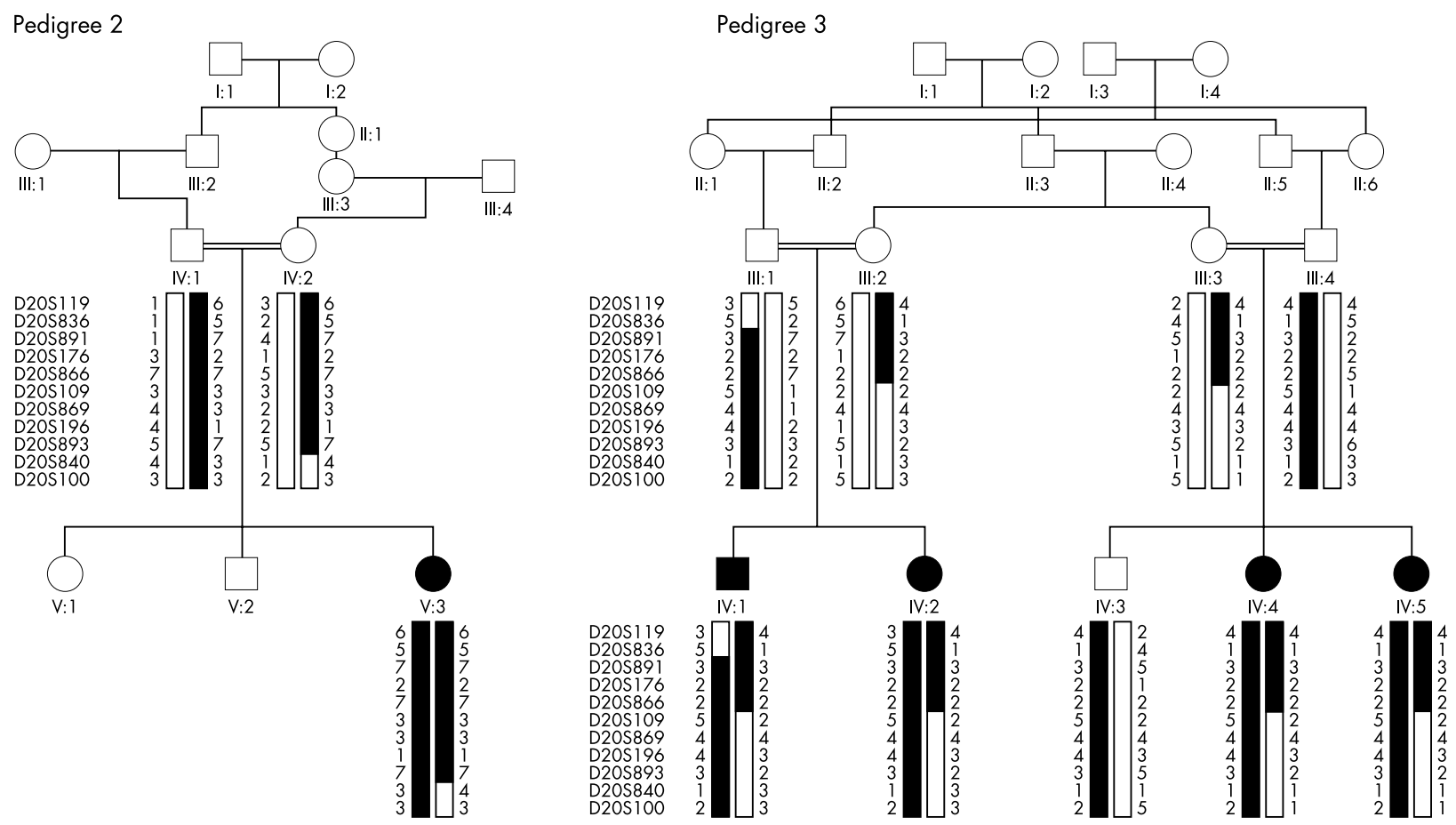

Figure 1 Pedigrees of the three consanguineous families. Pedigrees 1, 2, and 3 represent the Moroccan family 1, Moroccan family 2, and the Italian family respectively. Affected individuals are denoted by closed symbols, unaffected family members by open symbols, and individuals with unknown phenotype by open symbols with a question mark. Haplotypes for the chromosome 20 markers are shown below each family member for whom DNA was available. The solid portion of the bars indicates the haplotypes linked to the gene for ATS.

of 10 centimorgans (cM) was analysed on a capillary sequencer (ABI3100; Applied Biosystems). A pooled DNA sample, containing equimolar amounts of six affected individuals of family 1 , was analysed. The data were processed using Genescan and Genemapper software (Applied Biosystems). After the finding of suggestive lod scores in family 1 , the DNA of all individuals of the three families was further analysed with microsatellite markers from the Généthon genetic map. Markers were investigated on an ABI3100 capillary sequencer, and alleles were numbered according to length, with the shortest allele being assigned number 1. Haplotypes were constructed, assuming 
Table 1 Clinical features of the ATS patients

\begin{tabular}{|c|c|c|c|c|c|c|c|c|c|c|}
\hline \multirow[b]{2}{*}{ Family } & \multirow[b]{2}{*}{ Individual } & \multirow[b]{2}{*}{ Age } & \multicolumn{2}{|c|}{ Arterial anomalies } & \multirow[b]{2}{*}{ Skin } & \multirow[b]{2}{*}{ Hernia } & \multirow[b]{2}{*}{ Joint laxity } & \multirow{2}{*}{$\begin{array}{l}\text { Arachno } \\
\text { dactyly }\end{array}$} & \multirow{2}{*}{$\begin{array}{l}\text { Pectus } \\
\text { deformity }\end{array}$} & \multirow[b]{2}{*}{ Other findings } \\
\hline & & & Tortuosity & Arterial stenosis & & & & & & \\
\hline Pedigree & IV-2 & $18 y$ & + & - & HES & - & + & + & - & Long face, high palate \\
\hline \multirow{5}{*}{1} & IV-3 & $18 y$ & + & + & Soft & - & + & + & - & Long face, high palate \\
\hline & IV-4 & $17 y$ & + & - & Redundant & - & + & - & - & $\begin{array}{l}\text { Long face, micrognathia, } \\
\text { cleft palate }\end{array}$ \\
\hline & $\mathrm{IV}-5$ & $17 \mathrm{~m}$ & + & - & - & - & - & + & - & - \\
\hline & IV-9 & $9 y$ & + & - & Cutis laxa & - & + & - & + & Micrognathia, high palate \\
\hline & IV-10 & $8 y$ & + & - & Cutis laxa & - & + & - & + & Micrognathia, cleft palate \\
\hline $\begin{array}{l}\text { Pedigree } \\
2\end{array}$ & $\mathrm{~V}-3$ & $2 \mathrm{~m}$ & + & - & HES & + & + & + & + & $\begin{array}{l}\text { Micrognathia, cleft palate, } \\
\text { blepharophimosis, arterial } \\
\text { aneurysm }\end{array}$ \\
\hline \multirow[t]{4}{*}{$\begin{array}{l}\text { Pedigree } \\
3\end{array}$} & IV-1 & $21 y$ & + & - & Soft & + & + & - & - & $\begin{array}{l}\text { Soft nasal cartilage, } \\
\text { micrognathia, } \\
\text { hypothyroidism }\end{array}$ \\
\hline & IV-2 & $16 y$ & + & - & Soft & + & + & - & - & $\begin{array}{l}\text { Soft nasal cartilage, } \\
\text { micrognathia, keratoconus, } \\
\text { hypothyroidism }\end{array}$ \\
\hline & $\mathrm{IV}-4$ & $21 y$ & + & + & Laxity & - & + & - & - & $\begin{array}{l}\text { Soft nasal cartilage, } \\
\text { micrognathia }\end{array}$ \\
\hline & IV-5 & $19 y$ & + & + & Laxity & - & + & - & - & $\begin{array}{l}\text { Soft nasal cartilage, } \\
\text { micrognathia }\end{array}$ \\
\hline
\end{tabular}

the minimal number of recombinations, by tracing segregation of alleles in the families using the published marker order (fig l).

MLINK was used to calculate two-point lod scores between the ATS locus and the markers. The analysis was performed under the assumption of autosomal recessive inheritance of the phenotype with complete penetrance. Individual IV:1 of pedigree 1 was considered to have an unknown phenotype in the linkage analysis. The influence on the lod score is therefore 0 , but the inclusion of this sample was helpful in the reconstruction of the haplotypes. Equal allele frequencies were used in the linkage calculations. Although the use of incorrect allele frequencies may lead to false positive evidence of linkage under certain conditions, the power to detect true linkage remained unaffected. The frequency of the ATS was set at 0.00001. LINKMAP was used to perform multipoint linkage analysis using the marker order: centromere -D20S836-1.9 cM-D20S891-7.6 cM-D20S109-telomere.

\section{Mutation screening of the beta GIcNAc beta 1, 4- galactosyltransferase 5 Gene (B4GALT5)}

PCR products for each of the nine exons of the B4GALT5 gene were obtained for an affected individual of each of the three families (family1, IV-9; family2, V-3; family3, IV-4). Mutation screening was performed by direct sequencing of the PCR products using dye terminator chemistry (Applied Biosystems).

\section{RESULTS}

\section{Genomewide scan}

To map the ATS gene, a genomewide scan was performed by homozygosity mapping using pooled DNA from six affected individuals of family 1 (fig 1 ). Homozygosity mapping of autosomal recessive conditions in inbred families is based upon the fact that affected subjects will be homozygous for polymorphic markers in and around the disease locus due to inbreeding. In our genome scan, 400 polymorphic microsatellite markers, equally spread over the genome, were analysed. In the pool of six patients from family 1 this yielded 10 different markers with a single allele flanked at both sides by a marker with, at most, two different alleles. Subsequently, these 10 markers were typed for each individual member from family 1 . This revealed a two-point lod score of 4.11 at $\theta=0$ for marker D20S178 located in chromosome 20q13, whereas the other nine markers revealed lod scores lower than 1.5. Further analysis of the chromosome 20 q13 region was performed in all three ATS families using additional markers (fig 2) originating from the

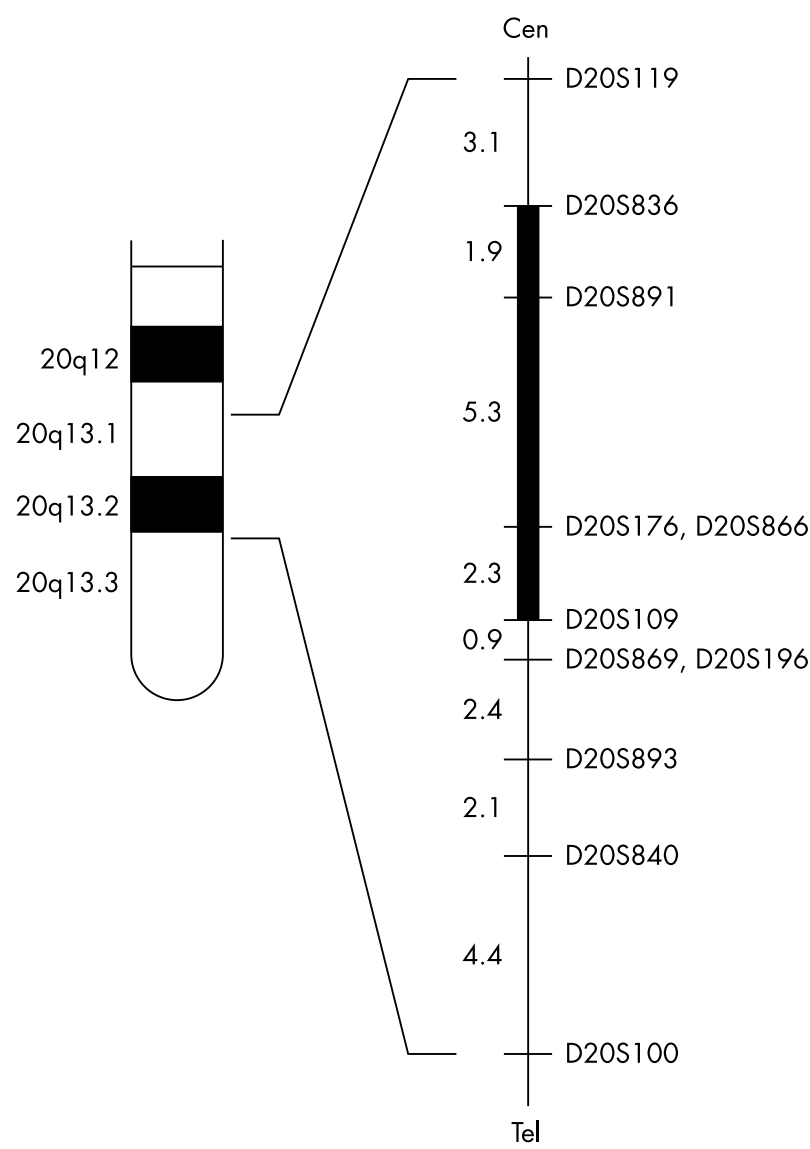

Figure 2 Linkage map of the markers used in the analysis. The genetic distances between the markers were deduced from the Généthon linkage $\mathrm{map}^{16}$, and are indicated in $\mathrm{CM}$. The candidate region for ATS syndrome is indicated in bold. 
Table 2 Two-point lod scores for markers at $20 q 13$

\begin{tabular}{|c|c|c|c|c|c|}
\hline \multirow[b]{2}{*}{ Marker } & \multirow[b]{2}{*}{ Theta } & \multicolumn{3}{|l|}{ Lod score } & \multirow[b]{2}{*}{$\mathrm{Z}_{\text {max }}$ combined } \\
\hline & & Ped 1 & Ped 2 & Ped 3 & \\
\hline D20S119 & 0.06 & 2.29 & 0.59 & 1.16 & 4.04 \\
\hline D20S836 & 0.06 & 2.46 & 0.59 & 1.14 & 4.19 \\
\hline D20S891 & 0.00 & 4.11 & 0.75 & 3.13 & 7.99 \\
\hline D20S176 & 0.00 & 2.17 & 0.75 & 2.19 & 5.11 \\
\hline D20S866 & 0.00 & 2.18 & 0.68 & 1.18 & 4.04 \\
\hline D20S109 & 0.04 & 3.80 & 0.50 & 0.00 & 4.30 \\
\hline D20S869 & 0.03 & 2.37 & 0.67 & 1.36 & 4.40 \\
\hline D20S196 & 0.04 & 2.01 & 0.65 & 0.33 & 2.99 \\
\hline D20S893 & 0.13 & 0.81 & 0.36 & 0.20 & 1.37 \\
\hline D20S840 & 0.14 & 0.79 & -0.09 & 0.69 & 1.39 \\
\hline D20S100 & 0.28 & 0.19 & 0.17 & -0.02 & 0.34 \\
\hline
\end{tabular}

Ped, pedigree.

Généthon genetic map. This yielded a combined maximum lod score of 7.99 at $\theta=0$ for D20S891 (table 2).

Lod scores calculated for the three families separately yielded a maximum of $4.11,0.75$, and 3.13 at $\theta=0$ for marker D20S891 for the Moroccan family 1, the Moroccan family 2 (the two possibly related families), and the Italian family, respectively (table 2 ). This suggests that the ATS gene in both the large Moroccan family 1 and the Italian family maps to this region on chromosome 20q13. The positive lod scores in the Moroccan family 2 with a single ATS patient is also compatible with linkage to the same region.

Normal haplotypes, as identified in carrier parents, were different from those segregating with the disease. The unaffected subjects were heterozygous or homozygous for the normal haplotypes. The individual with the unknown phenotype (individual IV-1 in Moroccan family 1) was homozygous for the disease haplotype, and might be affected. Multipoint linkage calculations between the ATS locus and markers D20S836, D20S891, and D20S109 revealed a maximum lod score of 7.99 at marker D20S891 (fig 3).

Haplotypes were constructed, revealing key recombinants between marker D20S836 and the ATS gene at the proximal side (Moroccan family 1 and Italian family), and between marker D20S109 and the ATS gene at the telomere side

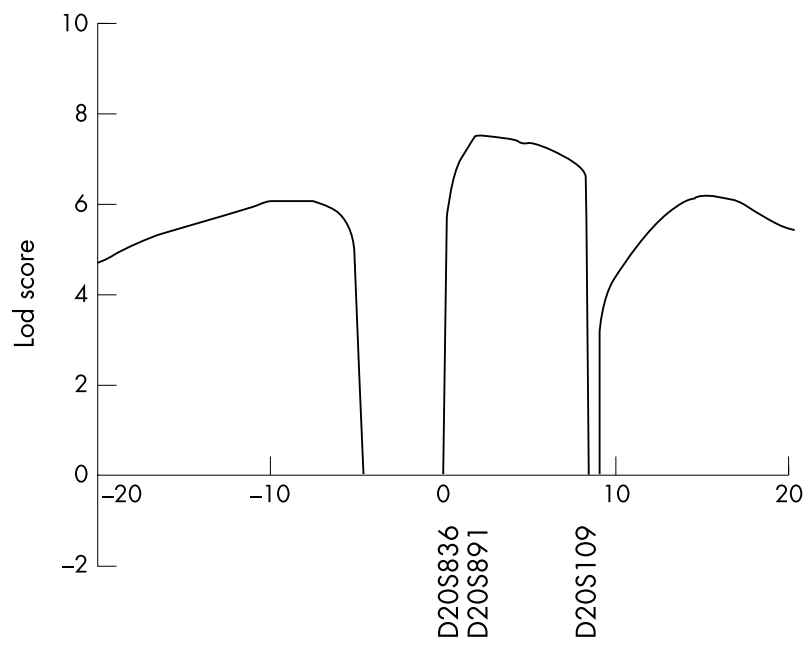

Genetic distance (cM)

Figure 3 Multipoint linkage analysis between ATS and three chromosome $20 \mathrm{q}$ markers. Curves indicate the likelihood that the ATS locus is at the map location with respect to the adjacent markers shown below the horizontal axis. The relative genetic position of D20S836 was arbitrarily placed at zero.
(Italian family) of the chromosome (fig 1). These recombinational events localise the gene for ATS between D20S836 and D20S109 in a genetic interval of 9.5 cM on the Généthon map (fig 2). On the draft sequence of the human genome in the National Center for Biotechnology Information (NCBI) database, this linkage interval corresponds to a physical candidate region of approximately 4.1 Mb.

\section{Candidate gene study in region of interest}

A computer search in the human genome resources of NCBI, ENSEMBL, and UCSC revealed over 30 positional candidate genes within the linkage interval between markers D20S836 and D20S109 on chromosome 20q. One of these, B4GALT5 (EC 2.4.1.22), encodes for beta 4 galactosyl transferase, one of the galactosyl transferases involved in the biosynthesis of glycosaminoglycans. ${ }^{11}$ This group of enzymes catalyses the transfer of galactose to galactose beta- $1,4-\mathrm{N}$-acetylglucosamine, during the formation of different glycoconjugates and saccharide structures. Mutations in another member of the galactosyl transferase gene family, B4GALT7 (EC 2.4.1.133), have been identified in patients with a progeroid variant of Ehlers-Danlos syndrome (EDS). ${ }^{12-14}$ As progeroid EDS disease shares some of the features of ATS, the B4GALT5 gene was considered a good candidate gene for ATS. Direct sequencing of the nine exons of B4GALT5 from an affected individual of each of the three ATS families showed no sequence alterations in the coding region. A substitution in intron 3 (IVS3-16 C $\rightarrow$ T) was identified in the two Moroccan families, and segregated completely with ATS in both. However, this mutation is an uncommon polymorphism in the Moroccan population (frequency of the T allele is 0.07 ). Other positional candidate genes are PRKCBP1, NCOA3, PREX, ARFGEF2, CSE1L, STAU, ARPC3B, DDX27, KCNB1, and PTGIS, among others. However, none of these genes is an obvious functional candidate for ATS.

\section{DISCUSSION}

In this study we describe the mapping of the gene for arterial tortuosity syndrome (ATS) to a small region on chromosome 20q13. Initially, a genomewide scan was performed on a DNA sample pooled from six affected individuals from a large consanguineous Moroccan family. A single region on the long arm of chromosome 20 was shared by all patients. The homozygosity mapping was confirmed by linkage analysis in three consanguineous ATS kindreds with a total of 11 patients. Multipoint linkage analysis yielded maximum lod scores of 7.99 at marker D20S89l on chromosome $20 \mathrm{ql3}$. Analysis of key recombinational events indicated a linkage region of $9.5 \mathrm{cM}$ on the Généthon genetic map (fig 2), which represents $4.1 \mathrm{Mb}$ on to the physical map of chromosome $20 \mathrm{q} 13$.

As only three ATS families were investigated, we cannot exclude genetic heterogeneity. However, as ATS is a rare disorder, but two and possibly three families are linked to the same locus, it could be speculated that there is only a single ATS locus.

Based on the different databases, the candidate region for ATS contains over 30 predicted genes. Although the theoretical search for plausible functional candidate genes for ATS is highly speculative, genes (or homologues of structural genes) involved in the extracellular matrix are possible candidates, particularly those involved in the elastogenesis pathway. All major arteries contain a large amount of elastic fibres consisting of elastin, which together with the fibrillins and microfibril associated proteins are responsible for elasticity. ${ }^{15}$ Mutations in FBN1 (Marfan's syndrome), FBN2 (Beal's syndrome), elastin (Williams' syndrome), fibulin 5 (cutis laxa type I) and ABCC6 (PXE) all give rise to abnormalities in the elastic network. However, 
these disease genes are not located in the linkage interval of ATS on chromosome 20q.

B4GALT5, a functional candidate gene for ATS located in the candidate interval, was excluded by mutation analysis in the patients. None of the remaining positional candidate genes has an obvious relationship with the extracellular matrix or the elastogenesis pathway. The mouse syntenic region of human chromosome $20 \mathrm{q} 13$ is located on chromosome 2q; however, no extra obvious candidate genes for ATS have been localised to this region.

In conclusion, we have identified a locus for ATS on chromosome 20q13, which is an important step in the identification of the ATS gene. Cloning and completing functional and structural analysis of the ATS gene may provide new insights into the molecular mechanisms of elastogenesis.

\section{ACKNOWLEDGEMENTS}

We thank Dr G Mancini, Dr Catsman, Dr J Hoogeboom and Prof M Breuning for help with the clinical study of the families, Dr W. Kleijer for patient fibroblasts and Dr D Halley for patient DNA. This work was supported by Fondazione Cariplo, 2001, Italy.

Electronic database Information. Online Mendelian Inheritance in Man (OMIM), http://www.ncbi.nlm.nih.gov/Omim/.Généthon, http://www.genethon.en/php/index.php/. National Centre for Biotechnology Information (NCBI), http://www.ncbi.nlm.nih.gov/.

University of California Santa Cruz (UCSC), http://genome.cse.ucsc. edu/. Ensembl database, http://www.ensembl.org/

\section{Authors' affiliations}

P J Coucke, P Van Acker, A De Paepe, Center for Medical Genetics, Ghent University Hospital, Ghent, Belgium

M W Wessels, Department of Clinical Genetics and Obstetrics and Gynecology, Erasmus University Medical Center, Rotterdam, The Netherlands

R Gardella, S Barlati, M Colombi, Division of Biology and Genetics, Department of Biomedical Sciences and Biotechnology, University of Brescia, Brescia, Italy

P J Willems, Synergene, Antwerp, Belgium

Correspondence to: Paul Coucke, Ghent University Hospital, Department of Medical Genetics, De Pintelaan 185, B-9000 Ghent, Belgium; paul.coucke@rug.ac.be

\section{REFERENCES}

1 Beuren AJ, Hort W, Kalbfleisch H, Muller H, Stoermer J. Dysplasia of the systemic and pulmonary arterial system with tortuosity and lengthening of the arteries. A new entity, diagnosed during life, and leading to coronary death in early childhood. Circulation 1969;39:109-15.

2 Lees MH, Menashe VD, Sunderland CO, Mgan CL, Dawson PJ. Ehlers-Danlos syndrome associated with multiple pulmonary artery stenoses and tortuous systemic arteries. J Pediat 1969;75:1031-136.

3 Welch JP, Aterman K, Day E, Roy DL. Familial aggregation of a "new" connective-tissue disorder: a nosologic problem. Birth Defects Orig Artic Ser 1971;7:204-113.

4 Ades LC, Knight WB, Byard RW, Bateman JF, Esquivel JA, Mee RB, Haan EA, Milewicz DM. Clinicopathologic findings in congenital aneurysms of the great vessels. Am J Med Genet 1996;66:289-99.

5 Pletcher BA, Fox JE, Boxer RA, Singh S, Blumenthal D, Cohen T, Brunson S, Tafreshi P, Kahn E. Four sibs with arterial tortuosity: description and review of the literature. Am J Med Genet 1996;66:121-8.

6 Al Fadley F, Al Manea W, Nykanen DG, Al Fadley A, Bulbul Z, Al Halees Z. Severe tortuosity and stenosis of the systemic, pulmonary and coronary vessels in 12 patients with similar phenotypic features: a new syndrome? Cardiol Young 2000;10:582-9.

7 Franceschini P, Guala A, Licata D, Di Cara G, Franceschini D. Arterial tortuosity syndrome. Am J Med Genet 2000;91:141-3.

8 Rivera IR, Gomes L, Moises VA, Silva CC, Andrade JL, Carvalho AC. Multiple arterial anomalies in the newborn infant. Echocardiographic and angiographic diagnosis. Arq Bras Cardiol 2000;75:137-44.

9 Wessels MW, Catsman-Berrevoets CE, Mancini G, et al. Three new families with arterial tortuosity syndrome. Submitted.

10 Gardella R, Zoppi N, Assanelli D, et al. Exclusion of candidate genes in a family with arterial tortuosity syndrome. Submitted.

11 Sato T, Furukawa K, Bakker H, Van den Eijnden DH, Van Die I. Molecular cloning of a human CDNA encoding beta-1, 4-galactosyltransferase with $37 \%$ identity to mammalian UDP-Gal:GlncNAc beta-1,4-galacotsyltransferase. Proc NatlAcad Sci USA 1998;95:472-7.

12 Quentin E, Gladen A, Roden L, Kresse H. A genetic defect in the biosynthesis of dermatan sulfate proteoglycan: galactosyltransferase I deficiency in fibroblasts from a patient with a progeroid syndrome. Proc Natl Acad Sci USA 1990;87:1342-6.

13 Okajima T, Fukumoto S, Furukawa K, Urano T. Molecular basis for the progeroid variant of Ehlers-Danlos syndrome. Identification and characterization of two mutations in galactosyltransferase I gene. J Biol Chem 1999;274:28841-4.

14 Almeida R, Levery SB, Mandel U, Kresse H, Schwientek T, Bennett EP, Clausen $\mathrm{H}$. Cloning and expression of a proteoglycan UDP-galactose:betaxylose beta-1,4-galactosyltransferase I: a seventh member of the human beta4-galactosyltransferase gene family. J Biol Chem 1999;274:26165-71.

15 Rosenbloom J, Abrams WR. Elastin and the microfibrillar apparatus. In: Royce PM and Steinmann B, eds. Connective Tissue and its heritable disorders. New York: Wiley-Liss, Inc, 2002:249-70.

16 Dib C, Faure S, Fizames C, Samson D, Drouot N, Vignal A, Millasseau P, Marc S, Hazan J, Seboun E, Lathrop M, Gyapay G, Morissette J, Weissenbach J. A comprehensive genetic map of the human genome based on 5,264 microsatellites. Nature 1996;14:152-4. 